\title{
Promoting New and Expanded Roles for Librarians and Information Specialists
}

\author{
Carla J. FUNK M.L.S, M.B.A., ${ }^{\mathrm{a}, 1}$ \\ ${ }^{a}$ Medical Library Association (retired)
}

\begin{abstract}
This chapter describes how the U.S. National Library of Medicine (NLM), under the leadership of Donald A. B. Lindberg M.D., promoted new and expanded roles for librarians and information specialists in response to advances in technology and public policy. These advances brought information services directly to all potential users, including health professionals and the public and stimulated NLM to expand its programs, policies, and services to serve all. Dr. Lindberg included librarians and information specialists in all of NLM's new endeavors, helping both to recognize and establish new or expanded roles. The involvement of librarians and information specialists in multidisciplinary healthcare research teams, in underserved communities, and in research data management and compliance has helped to redefine the health sciences information profession for the 21 st century.
\end{abstract}

Keywords: Donald A.B. Lindberg M.D., U.S. National Library of Medicine, Librarians, Access to Information

\section{Introduction}

The work of health sciences librarians and information specialists changed substantially in the two decades before Donald A.B. Lindberg M.D. arrived as Director of the U.S. National Library of Medicine (NLM) in 1984. Major change agents included: implementation of the Regional Medical Library (RML) Network and NLM grant programs; great expansion in the number of medical libraries and the size of collections; the advent of MEDLINE (1971) and other online databases; development of shared bibliographic utilities and serial holdings databases; and automated support for internal library operations [1]. These and other developments required many librarians to acquire new knowledge and skills, including expertise in online searching. Demand for online searches and document delivery exploded. Time required for acquisitions and cataloging declined. New opportunities for librarians in education, research, and resource and service development emerged.

Some notable results included: the first clinical medical librarian programs; the concept of Integrated Academic Information Management Systems (IAIMS); and early systems enabling individual health professionals and students to search MEDLINE subsets in some medical schools and teaching hospitals [2-5].

The developments from 1965 to 1984 transformed how many health sciences librarians and information specialists performed their work, but had less effect on the health professionals, researchers, students, and, in some cases, the patients they served.

\footnotetext{
${ }^{1}$ Corresponding Author, Carla j. Funk, 345 West Fullerton Parkway, Apt. 2701, Chicago, IL 60614,USA; Email: cjfunk46@gmail.com
} 
In 1984, however, significant changes in the technology affordable to users, in the expansion of electronic information sources, and in user expectations were on the near horizon. These changes would have an even greater impact on the roles librarians and information specialists performed.

I first became of aware of Don Lindberg in 1984 when he was appointed Director of NLM and I was working as a librarian for the American Medical Association (AMA). Don's appointment was very disappointing to some in the medical library community because we hoped a librarian would be appointed to the position. We did not realize that his groundbreaking achievements in medical informatics, his experience as professor and chair of the Department of Information Science at the University of Missouri-Columbia's School of Library and Information Science, his role as an advisor to the IAIMS study, and his high regard for librarians' expertise would prove to be key to the expansion and evolution of the medical library profession into what it is today.

Don arrived at NLM at the point when personal computers made it technically feasible, but not yet easy, for individual health professionals to access MEDLINE and other NLM databases from offices and homes. He envisioned a future in which biomedical knowledge would be directly accessible from electronic health records (EHRs) for the benefit of health professionals and patients. He believed NLM could and should hasten the day when biomedical knowledge and data were readily available to health professionals, biomedical researchers, students, and patients - when and where they needed it. As quickly became clear to those who had direct contact with him, Don expected librarians and information specialists to be part of the multidisciplinary workforce needed to make this future a reality. He also expected librarians to have expanded responsibilities and stature within this future.

Don included librarians as key participants, and often leaders, in all of the major projects he initiated at NLM. In a planning process he also initiated, the NLM Board of Regents appointed many external librarians to the purposefully multidisciplinary panels convened to develop the 1986-2006 NLM Long Range Plan and all subsequent NLM planning documents [6]. For planning, Don believed "you should start out with the people you're trying to serve and find out from them what would actually help and what's possible," a philosophy that changed the programs, products, and services of NLM and strongly influenced the roles that health sciences librarians assumed in the ensuing decades [7,p.21]. Throughout Don's tenure, NLM's plans consistently addressed the need to prepare librarians for important contributions in the changing biomedical and health environment [8].

Under Don's leadership, NLM supported new and expanded roles for librarians and information specialists in many ways. NLM's influence on the expansion of education and training opportunities for librarians is summarized by Holst [9]. In contrast, this chapter highlights: the intertwined impacts of advances in technology and public policy; the re-orientation of the Regional Medical Library (RML) Network to reach individual health professionals and the public; the expansion of NLM programs, products, and services; and the expansion of librarians' research roles.

\section{Bringing Information Services to Users and Potential Users}

Upon arriving at NLM, Don took immediate steps to develop an inexpensive userfriendly interface to MEDLINE to encourage searching from the increasing numbers of personal computers in physicians' offices and homes [10]. Less than two years later, in 
February 1986, NLM's Grateful Med software package joined the emerging array of systems aimed at physicians without specialized search training. Aided by the recently established Friends of the National Library of Medicine (FNLM), NLM began an active campaign to publicize Grateful Med directly to health professionals, as well as to librarians in the RML network. Soon thereafter, Congress encouraged NLM "to develop an outreach program aimed at .... [the] transfer of the latest scientific findings to all health professionals... in rural communities and other areas .... NLM's mission was explicitly amended to add the function to "Publicize the availability of[its] products and services..." [11].

Responding to Congress, the NLM Board of Regents convened a distinguished multidisciplinary outreach planning panel in 1988, chaired by Michael E. DeBakey M.D. The Panel's 1989 report, Improving Health Professionals Access to Information, found the majority of health professionals were unaffiliated with a library. In addition to advocating for increased support for connecting hospitals to the Internet and expansion of medical informatics training and IAIMS grants, the report encouraged NLM to refocus the RML Network on outreach to individual health professionals, especially underserved health professionals, to help them access national biomedical information sources. "To do this, the RMLs should act as a "field force" for NLM products and services, providing information and services to health professionals directly and through network libraries" [12]. Dr. DeBakey and the report were influential in obtaining additional Congressional funding for the renamed National Network of Libraries of Medicine (NN/LM).

As Humphreys noted in a lecture on historic relationships between NLM and health sciences librarians at the 2001 annual meeting of the Medical Library Association (MLA), "the greatest friction...occurs when there is a fundamental change in the way NLM carries out its mission..." [13]. And Don did promote change, especially in the area of providing medical and health information to all through the creative use of existing technologies.

The promotion of Grateful Med by NLM to the healthcare community at large and the use of network librarians as a "field force" to encourage unaffiliated health professionals to use it resulted in a display of this "friction" in an infamous standing room only debate between Don and Herb White, professor of library science at Indiana University-Bloomington, at the May 1992 MLA Annual Meeting (which, coincidentally, was my first Annual Meeting as MLA Executive Director). Many librarians in academic institutions and teaching hospitals already had their hands full teaching online searching and providing user-friendly search interfaces, including Grateful Med, for their own faculty, staff, and students. Other librarians, especially in hospitals, were fearful their jobs would be cut if administrators thought that health professionals could locate information on their own.

In Don's view the "role of the health sciences librarian in the 1990's is to be recognized...as an authority on access to information related to the biosciences" [14,p.72]. He also referred to MLA's educational policy statement, "Platform for Change," focusing on the individual's responsibility for lifelong learning. This would be crucial in encouraging health sciences librarians to learn new roles as the technology continued to evolve throughout the coming decades. White countered that NLM's "databases cannot be properly used without enough medical library intermediaries" and Grateful Med is only one source of medical information [15].

However, history demonstrates that Don's broader perspective prevailed. Direct access to electronic information sources by health professionals was inevitable and 
valuable; systematic reviews and other complex searches for evidence required trained search experts.

The NN/LM personified Don's concept of a "network" providing "training on NLM information resources, funding of local and regional projects, and coordination of medical library services" [6]. Although resisted by some, the initial Grateful Med outreach projects (1990-92) encouraged some librarians to take on the role of teaching underserved health professionals not affiliated with their institutions and helping them to connect to library services. They provided useful lessons learned for the many subsequent NN/LM supported outreach efforts [10].

Meanwhile, access to the Internet was increasing, and NLM had begun to fund Internet connections for hospitals. Soon after the Lindberg-White debate in 1992, NLM organized, and MLA co-sponsored a satellite broadcast entitled "Information STAT! Rx for Hospital Quality" stressing the importance of hospitals' connecting to the Internet and the value of libraries and librarians in improving hospital quality and cost effectiveness [16]. The program featured hospital librarians, physicians, and other health professionals, with videos of existing advanced services and outreach programs. It provided a good picture of the power of hospital library services in combination with Internet connections.

By the end of 1990, a basic World Wide Web system had been launched. In 1993, the first Web browser demonstrated its value for the general population - and as a universal interface for information service providers. By 1997, the spread of the Internet and Web-capable workstations enabled NLM to provide free access to MEDLINE worldwide via PubMed for anyone with a Web browser. (Previous NLM charges for online searching covered the cost of commercial telecommunications.)

NLM's MedlinePlus.gov consumer health web information service and web interfaces to other NLM information services soon followed. Once NLM online services were free on the Web and directed toward a broader range of users, the NN/LM supported librarians in greatly expanded outreach to, and collaboration with, health professionals, researchers, public health departments, the HIV/AIDS affected community, public libraries, other community-based organizations, as well as the general public [17]. Inexpensive "smart" hand-held devices further expanded the universe of potential users and the range of circumstances, e.g., travel, emergencies, disasters, in which information was accessible.

Effective outreach involves listening and learning about people's information needs, making them aware of available information sources and access tools, and facilitating their use of these resources. This is now an important and enduring role for health sciences librarians and information specialists. Prior to the 1990s, many librarians were primarily focused on those who came to the library seeking service. Now librarians are out among current users and potential users. Many are embedded with users to better understand and meet their real information needs. Under Don's leadership, NLM and the $\mathrm{NN} / \mathrm{LM}$ helped to hasten this transition.

\section{New and Expanded Information Roles}

Any new NLM program, service, or initiative raises the potential for new roles for librarians and information specialists. During Don's 30-year tenure as director, the expansion of NLM's scope was remarkable, e.g., bioinformatics, advanced imaging, consumer health information, clinical trials data, health data standards, disaster 
information management, and support for compliance with new requirements for public access to research results and electronic health records (EHRs). Don encouraged NLM staff to seek help from health sciences librarians whenever it embarked on any new endeavor. He also encouraged NLM staff to assist, highlight, and applaud librarians as they embarked on new roles. NLM assistance sometimes involved training for specialized roles, e.g., in consumer health and in disaster information, as described by Holst [9]. This chapter provides examples of other ways NLM helped to foster new roles for librarians and information specialists.

\subsection{Support for Informationists}

The concept of the "informationist' was proposed by Frank Davidoff M.D. and Valerie Florance Ph.D. in 2000 [18]. They characterized these new professionals as knowledge workers formally trained in both clinical sciences and information sciences so they can retrieve, synthesize, and present medical information routinely as members of clinical health care teams. "Informationists" were distinguished from clinical librarians primarily by their training in biomedical as well as information science and their position as specialists embedded within their teams. Not long after the introduction of the concept, informationists were practicing in a variety of settings, including clinical, biomedical research, and public health. The NIH Library, under the direction of Suzanne Grefsheim M.Ed, M.S.L.S. and with the support of John Gallin M.D., Director of the NIH Clinical Center, pioneered the use of informationists in clinical research.

On April 4-5, 2002, a conference organized by MLA to facilitate a national discussion of the informationist concept took place at NLM, which also provided financial support. The librarians and health professionals who participated in the conference concluded:

The informationist concept meets a critical need for an intermediary between the expanding information universe and practitioners. ... Persuading people to become informationists and users of informationists' services will require successful and visible model projects. Training entrants to the role must combine formal educational programs, apprenticeships or mentorships, structured clinical learning experiences, and peer-to-peer teaching [19].

Beginning in 2003, NLM took steps to meet these needs, under the direction of Dr. Valerie Florance, then NLM Associate Director for Extramural Programs. She first established an NLM grant program for budding informationists, the NLM Individual Fellowship for Informationist Training. This fellowship program supported coursework and internships in clinical, biomedical research, public health, and consumer health to prepare Fellows for new career directions. This program concluded in 2008. It was followed in 2010 by Administrative Supplements for Informationist Services, another brainchild of Dr. Florance. Funded by NLM and other NIH institutes, this program provided grants for NIH-funded extramural researchers to immerse informationists in their research teams, often to assist with research data management. These grant programs improved research skills and knowledge about the research community, as well as developing best practices and demonstrating the roles information specialists could play in research data management [20-21]. 


\subsection{Health Information Literacy}

NLM recognized health information literacy as a necessity if patients and the public at large were to understand and evaluate the information that Web services and librarians were providing to them. In the $2000 \mathrm{~s}$, a health literacy gap among the general population was being reported through a number of studies by The Joint Commission, the American Medical Association, the Agency for Healthcare Research and Quality, the US Department of Education, the Institute of Medicine (now the National Academy of Medicine), and the U.S. Department of Health and Human Services. In one of my periodic meetings with Don and Betsy Humphreys as MLA's Executive Director, they brought up health literacy and health information literacy as challenges which health sciences librarians could help to address.

A search of the NLM's PubMed database in early 2009 showed a $2900 \%$ increase in articles about "health literacy" from 1998 through 2008 confirming that this was an increasingly important topic. A study by Shipman, Kurtz-Rossi, and Funk, funded by NLM, surveyed hospital administrators and health care providers about consumer health information and developed a curriculum to be taught by librarians to increase awareness of health literacy issues, encourage the use of NLM consumer resources such as MedlinePlus and Information Rx, and promote the role of librarians as key providers of consumer health information resources and services [22]. Again, support by NLM both financially and by NLM staff, including Elliot Siegel and Rob Logan, was crucial in the study and promotion of this important role of health sciences librarians.

\subsection{Electronic Patient Records and Health Sciences Librarians}

The 1994 Joint Commission standards for health care organizations integrated the information management function, encompassing patient-specific information, aggregate and comparative patient data, and knowledge-based information (the traditional library collections and services). Although threatening to the status quo for hospital libraries, the functional approach opened potential new roles for hospital librarians, just as the IAIMS concept did for academic health sciences librarians and provided a platform for working with hospital colleagues and vendors on connections between electronic knowledge resources and EHRs as both became more prevalent [23].

In a 2005 perspective speculating about the future of medical libraries in the next decade, Don and Betsy re-envisioned broad deployment of EHRs providing "enhanced opportunities to deliver customized information when and where it is needed." These would include "...remote consultations with information specialists," who as members of the health care team could "tailor summarized evidence to the specific patient," based on data in the EHR [24]. By 2009, Don was particularly interested in the potential of personal health records and their ability to give individuals greater input to and control over their health care and their data. Prompted by him, that year an MLA/NLM Joint Electronic Personal Health Record Task Force was established to explore health sciences librarians' roles in linking patient records to knowledge-based information to support decision-making.

As one outcome, Don and MLA's president co-signed a 2009 letter to personal health record vendors recommending the inclusion in their products of a statement with links to MedlinePlus, MLA information about high quality health information, and pointers for obtaining librarian assistance. A copy of the letter was forwarded to the Joint Commission on the Accreditation of Healthcare Organizations (now The Joint 
Commission) [25]. In response, The Joint Commission added stipulations about access to knowledge-based information from EHRs to its accreditation standards, adding another potential responsibility to health sciences librarians' jobs and strengthening their value to their institutions. Such connections were later mandated in EHR requirements issued by the U.S. Department of Health and Human Services (HHS).

\subsection{Compliance with Requirements for Public Access to Research Results}

The increase in research articles published in MLA's journal in the years following Don's arrival at NLM has been well documented [26-27]. MLA strongly encouraged research in its 1987 strategic plan, which called for "leadership in research in health information science," and NLM's actions during Don's tenure also had a positive effect [28].

Don was a strong advocate of multidisciplinary research teams. During his interviews for the NLM directorship, he asked Lois Ann Colaianni, Associate Director for Library Operations, "what were her expectations, what would she like, and she essentially said she thought that the librarians could do some research. And I said, ... if I come here, they're going to get ample opportunity to do research. That I can guarantee you" [7,p.16].

Don quickly made good on that promise by including librarians at NLM, RMLs, and other network libraries in new projects he initiated not long after his arrival, e.g., the Unified Medical Language System, the evaluation of MEDLINE CD-ROM products, and the Critical Incident Technique (CIT) study [29-31]. Don also encouraged NLM's staff to include research-related projects in the experiences offered to participants in the NLM Associate Fellowship Program, a practice which also helped to expand the cadre of librarians participating in research.

Conducting research was not a new role for health sciences librarians, although it started to expand in the late 1980s. In the 2000s and 2010s, in addition to NLM's encouragement of the use of research informationists, new NLM services and related policy developments encouraged the emergence of new roles related to research compliance.

In February 2000 (the joint timing was coincidental), NLM released PubMed Central (PMC), an NIH-initiated free electronic archive of full text articles from biomedical journals, and ClinicalTrials.gov, a free NIH registry of clinical trials of drugs for serious and life-threatening conditions - established in response to a 1997 law. NLM was assigned responsibility for both developments by NIH Director Harold Varmus M.D. In the case of PMC, the goal was to provide an alternative to expensive and restrictive access to online biomedical journals, which was frustrating to scientists, as well as librarians, especially in comparison to free and easy access to MEDLINE and genomic data. In the case of ClinicalTrails.gov, the Congressional intent was to help more patients gain access to trials that might help them.

Once developed, however, PMC and ClinicalTrials.gov became key enablers of new public policies that emerged from separate series of events involving research advocacy groups, librarians and their professional associations, scientists, patients, journal editors, and the Congress. For PMC, the precipitating issue was lack of public access to the results of taxpayer-funded research. For ClinicalTrials.gov, it was outrage over deliberate omission of information about serious adverse drug effects in articles reporting the results of clinical trials. By late 2007, in separate actions, the U.S. Congress had mandated: (1) deposit in PMC of papers resulting from research funded by NIH, i.e., the 
NIH Public Access Policy, and (2) early registration and summary results submission in ClinicalTrials.gov for the majority of trials of drugs and devices subject to regulation by the U.S. Food and Drug Administration (FDA). Many other research papers and trials became subject to similar requirements promulgated by other research funders. Early and complete registration of clinical trials has been required for subsequent publication of results in many influential journals since 2005.

The new requirements were highly beneficial to the public and to the missions of NIH, NLM, and health sciences and research libraries in general. As the policies were developing and evolving, NLM kept health sciences and research librarians informed and encouraged their efforts to educate and assist investigators within their institutions in meeting their new responsibilities. In many cases, new relationships were established between librarians and their institution's offices of sponsored research. Once laws were passed, serious penalties for non-compliance were defined, and prospects for enforcement increased, formal institution-wide approaches for assisting and monitoring compliance by individual investigators were needed to avoid serious consequences for the whole institution, e.g., denial of future research funding.

Librarians in grantee institutions were instrumental in working with the NLM's National Center for Biotechnology Information (NCBI) to define and test reporting capabilities that provide an institution-wide view of missing or stalled submissions of author manuscripts to PMC so that corrective action can be taken. Librarians and information specialists in institutions with NIH Clinical and Translational Science Awards (CTSAs) were among the first to set up regular interactions with NLM's ClinicalTrials.gov team to provide specific feedback on problems being encountered in expanded trial registration and results submission. They also promoted centralized support within their institutions for meeting the new requirements. Librarians' existing relationships with NLM and its staff served their institutions well in advancing compliance with the new requirements and helped to raise their profile within the research enterprise.

\section{Conclusion}

Don Lindberg involved librarians in every important research or development program at NLM described in this chapter and elsewhere. He was very focused on the education and training of the library workforce as evidenced by the multiple task forces, programs, and studies on these topics instituted during his tenure at NLM [9]. As Linda Watson, retired director of the Health Sciences Library, University of Minnesota and MLA past president, commented to Don in his oral history interview, "NLM programs and services have helped librarians to be able to continue to reinvent themselves. Whether it's outreach, whether it's informationist concepts, whether it's patient care, disaster, you've given us the tools to be able to reinvent ourselves successfully" [7,p.41].

I treasured the years I worked with and learned from Don. After a somewhat rocky start at MLA's 1992 Annual Meeting, the relationship developed into a mutually supportive experience where the library community encouraged NLM to make access to the databases free to the public which he did, and NLM supported a number of initiatives including health information literacy, expanded roles for hospital librarians, and the education and training for health sciences librarians. Don broadened my perspectives as well as that of health sciences librarians through his willingness to meet, meaningfully interact, listen, and learn. In my role as MLA Executive Director, I met with Don once 
or twice a year for almost twenty years to exchange information about both of our organizations' programs and activities and the ways we could support each other and educate and evolve the profession to get quality health information to a variety of audiences. Don also attended MLA Board meetings when possible, gave an annual NLM update to the health sciences library community at MLA's annual meeting, and placed an MLA representative on the Friends of the National Library of Medicine, a group which he helped establish in 1986.

At his retirement event in 2015, Linda Walton M.L.S., MLA past president, eloquently summed up Don's impact on the health sciences library community saying, "Your fearless spirit of envisioning the next gateway of necessary tools and resources, and your willingness to prove nothing less than extraordinary has challenged us. From end-user searching, to bioinformatics, to disaster preparedness, you have led the way for librarians to develop and expand their expertise through the use of technology. This could only have happened because of your vision and the outstanding programs that NLM provides to the health sciences library community" [32].

\section{References}

[1] Meyerhoff E. Foundations of medical librarianship. Bull Med Libr Assoc. 1977 Oct;65(4):409-418.

[2] Cimpl K. Clinical medical librarianship: a review of the literature. Bull Med Libr Assoc. 1985 Jan;73(1):21-28.

[3] Matheson N, Cooper JAD. Academic information in the academic health sciences center: roles for the library in information management. J Med Educ. 1982 Oct;57(10, pt.2): 1-93.

[4] Bonham MD, Nelson LL. An evaluation of four end-user systems for searching MEDLINE. Bull Med Libr Assoc 1988 Apr; (76)2:171-180.

[5] Broering NC. The miniMEDLINE SYSTEMTM: a library-based end-user search system. Bull Med Libr Assoc 1985 Apr; (73)2: 138-145.

[6] National Library of Medicine (U.S.). Network of the National Library of Medicine. https://nnlm.gov

[7] Donald A.B. Lindberg, M.D. interview by Linda A. Watson. [Internet] October 31, 2014 [cited 2021 July 24], transcript, MLA Oral Histories. Medical Library Association, Chicago, IL. Available from: https://www.mlanet.org/blog/lindberg-donald-ab-md

[8] National Library of Medicine (U.S.). NLM long range planning documents. Available from: https://www.nlm.nih.gov/pubs/reports.html

[9] Holst R. Partnering for education and career development of librarians and information specialists. In: Humphreys BL, Logan RA, Miller RA, Siegel ER, editors. Transforming biomedical informatics and health information access: Don Lindberg and the U.S. National Library of Medicine. Amsterdam: IOS Press; 2021.

[10] Dorsch JL, Faughnan JG, Humphreys BL. Grateful Med: direct access to MEDLINE for health professionals with personal computers. In: Humphreys BL, Logan RA, Miller RA, Siegel ER, editors. Transforming biomedical informatics and health information access: Don Lindberg and the U.S. National Library of Medicine. Amsterdam: IOS Press; 2021.

[11] H.J.Res.395 - a joint resolution making further continuing appropriations for the fiscal year 1988, and for other purposes, Pub. L. 100-202, sec. 215 (22 Dec 1987).

[12] National Library of Medicine (U.S.). Board of Regents. Improving health professionals access to information: challenges and opportunities for the National Library of Medicine. National Institutes of Health, 1989.

[13] Humphreys BL. Adjusting to progress: interactions between the NLM and health sciences librarians, 1961-2001. J Med Libr Assoc. 2002 Jan;(90)1:19.

[14] Lindberg DAB. National Library of Medicine and its role. Bull Med Libr Assoc. 1993 Jan; (81)1:71-73.

[15] White HS. The Grateful Med program and the medical library profession. Bull Med Libr Assoc. 1993 Jan;(81)1:73-75.

[16] Information STAT: Rx for Hospital Quality. NLM News. 1992 Nov-Dec; 47(11-12):8-10.

[17] Shipman JP, Burroughs CM, Rambo N. NLM's library network: a force for outreach. In: Humphreys BL, Logan RA Miller RA, Siegel ER, editors. Transforming biomedical informatics and health information access: Don Lindberg and the U.S. National Library of Medicine. Amsterdam: IOS Press; 2021. 
[18] Davidoff F, Florance V. The informationist: a new health profession? Ann Intern Med. 2000 June;132(12): 996-998. DOI 10.7326/0003-4819-132-12-200006200-00012.

[19] Shipman JP, Cunningham DJ, Holst R, Watson LA. The informationist conference: report. J Med Libr Assoc. 2002 Oct;90(4):458-64.

[20] Deardorff AA, Florance V, VanBiervliet A. Assessing the National Library of Medicine's informationist awards. J Esci Libr. 2016;5(1): e1095. DOI: 10.7191/jeslib.2016.1095.

[21] Gore SA. A librarian by any other name: the role of the informationist. J E-sci Libr. 2013;2(1): 20-24. DOI 10.7191/jeslib.2013.1041

[22] Shipman JP, Kurtz-Rossi S, Funk CJ. The health information literacy research project. J Med Libr Assoc. 2009 Oct;(97)4: 273-281. DOI 10.3163/1536-5050.97.4.011

[23] Doyle JD. IAIMS and JCAHO: implications for hospital librarians. Integrated Academic Information Management Systems. Joint Commission on Accreditation of Healthcare Organizations. Bull Med Libr Assoc. 1999 Oct; 87(4): 383-386.

[24] Lindberg DAB, Humphreys BL. 2015 - the future of medical libraries. New Engl J Med. 2005 Mar;352(11): 1067-1070. DOI 10.1056/NEJMp048190.

[25] Jones DA, Shipman JP, Plaut DA, Selden CR. Characteristics of personal health records: findings of the Medical Library Association/National Library of Medicine Joint Electronic Personal Health Record Task Force. J Med Libr Assoc. 2010 Jul;98(3):243-249. DOI 10.3163/1536-5050.98.3.013.

[26] Gore SA, Nordberg JM, Palmer LA, Piorun ME. Trends in health sciences library and information science research: an analysis of research publications in the BMLA and JMLA from 1991-2001. J Med Libr Assoc. 2009 Jul;97(3):203-216. DOI 10.3163/1536-5050.97.3.009.

[27] Funk, ME. Our words, our story: a textual analysis of articles published in the BMLA/JMLA from 19612010. J Med Libr Assoc. 2013 Jan;1 0(1):12-20. DOI 10.3163/1536-5050.101.1.003

[28] Medical Library Association (Chicago, IL). Shaping the future: MLA's strategic plan. 1987.

[29] Humphreys BL, Tuttle MS. Something new and different: the Unified Medical Language System. In: Humphreys BL, Logan RA, Miller RA, Siegel ER, editors. Transforming biomedical informatics and health information access: Don Lindberg and the U.S. National Library of Medicine. Amsterdam: IOS Press; 2021.

[30] Woodsmall RM, Lyon-Hartmann B, Siegel ER editors. MEDLINE on CD-ROM: National Library of Medicine evaluation forum, Bethesda, Maryland, September 23, 1988. Medford, NJ: Learned Information, 1989. DOI.org/10.7326/0003-4819-111-3-266_3

[31] Lindberg DA, Siegel ER, Rapp BA, Wallingford KT, Wilson SR. Use of MEDLINE by physicians for clinical problem solving. JAMA. 1993 Jun 23-30;269(24):3124-9.

[32] National Library of Medicine director Donald A. B. Lindberg retires. MLA News 2015 May; 55(5):7. 